\title{
Xenia Hotels in Greece: A Holistic Approach to Modern
}

\section{Cultural Heritage}

\author{
Zoe Georgiadou, Dionisia Frangou and Dimitris Marnellos \\ Department of Interior Architecture, Decorative Arts and Design, Technological Educational Institution of Athens, Athens 12243, \\ Greece
}

\begin{abstract}
In the early 1950s, the Greek National Tourism Organization made a nation-wide attempt to develop tourism in Greece. For a period of two decades, it developed the hotel buildings' substructure, a project known as the "Xenia project". During this period, Greek architects, devoted to modernism, designed and supervised 53 hotel compounds, which spread throughout the country. Today, the Xenia Hotels are internationally recognized as part of Greece's modern cultural heritage, based on the simplicity, the definition of the form and the truth in materials use, besides the integration of the buildings in the natural environment, components which reveal themselves as a unique venture. This paper aims to reveal that, despite the efforts to retain the Xenia Hotels, these procedures remain incomplete. They rightly focus on architectural shells, morphological and functional standardization, proper utilization of the Greek environmental conditions, and the use of authentic local materials. However, the cultural evaluation of these settlements can only be completed by their holistic design, which also comprises their interior spaces, lightening and furniture design, all these detailed aspects that form an organic entirety and which are not included in these efforts.
\end{abstract}

Key words: Xenia Hotels, modern cultural heritage, holistic design, architectural approach, interior design, furniture design.

\section{Introduction}

The GNTO (Greek National Tourism Organization) in the early 1950s, within the national effort towards an economical reconstruction of the country after World War II and the Greek Civil War ${ }^{1}$, made a severe nation-wide attempt to develop tourism in Greece. The field of tourism had already been a priority for the Greek economy since 1914, under different forms of state supervision and control $^{2}$. The

Corresponding author: Zoe Georgiadou, Ph.D., professor, research fields: architecture, interior architecture, sociology of space, constructive and decorative materials, and space design. E-mail: zoegeo@teiath.gr.

${ }^{1}$ The Greek Civil War fought from 1943-1949, after World War II.

${ }^{2} 1914$ (Tourism Bureau), 1929 (Greek National Tourism Organization in a primary form), 1936 (Sub-ministry of Press and Tourism), 1941 (Directory of Spa-Towns and Tourism), 1945 (General Secretariat of Tourism), 1950 to today (Greek National Tourism Organization), 2004 as part of the Ministry for Tourism Development, and from 2010, as part of the Ministry of Culture and Tourism, recently from January 27, 2015 as part of the Ministry of Education, Religion, Culture and Tourism.
GNTO Council, which consisted of 10 members that specialized in tourism, exerted the tourism policies of the organization planned and executed within the development of the Xenia Hotels project, connecting it with economy and qualitative tourism [1]. On a national level, this project defines the most important attempt for mass production of public buildings, under state supervision and funding. The technical bureau of the organization, staffed by trusted architects, undertook the responsibility to organize and support the Xenia project by developing, for a period of about two decades, the hotel building substructures in different "hoteling" types. The main goal of this project was the "creation of standards in hotel resorts", built in Greek regions with exceptional natural beauty and tourist interest, and insufficient or non-existent infrastructures. This project's policy was meant "to offer tourists accommodation in high class hotels, and also to show private investors the aspired level of the new hotel facilities that should be constructed in order to develop tourism as the new profitable, financial 
field in which the state aimed for"

During this period, starting from 1950 to 1957 , Charalampos Sfaellos as head of the organization's technical bureau and then Aris Konstantinidis from 1957 to 1967, with a team of young Greek architects, most of them devoted to modernism [2], such as Jason Triantafyllidis, Phillipos Vokos, Christos Bougatsos, Costas Kitsikis, Constantinos Stamatis, Dionisis Zivas, George Nikoletopoulos, Katerina Dialisma, Kleon Krantonellis, and also Dimitris Pikionis, designed and supervised, as technical bureau's employees, 53 hotel compounds, motels and tourist pavilions ${ }^{4}$, which spread throughout Greek regions of the mainland and the islands, with archaeological, topological or other touristic interest.

The Xenia project was completed in 1974 and officially terminated in 1983. However, since 1970, coming to a climax in 1980, many of these model hotel resorts started to decline, and were abandoned, left void and unoccupied (Xenia of Andros island, Florina, Nafplio, etc.). Some were demolished with irregular procedures (Xenia of Chania, Heraklion, Joannina), some were leased under unfavorable terms, without defining regulations for preservation, expansion and architectural interventions (Xenia of Poros island, Mykonos island, Mesologgi, Drama, Nafplio, etc.), some had their use changed (Xenia of Delphi, Olympia, Volos, Rethymno, Igoumenitsa, etc.) and the rest were transferred to the HRADF (Hellenic Republic Asset Development Fund) ${ }^{5}$ properties, and were divested for reducing the public debt burden-Xenia of Paliouri Chalkidiki and Skiathos island have already been assigned since 2013 .

\footnotetext{
${ }^{3}$ According to GNTO Council's goals and objectives for Xenia project.

${ }^{4}$ The total number of the buildings produced within the Xenia project was about 70 (GNTO archives).

${ }^{5}$ The Hellenic Republic Asset Development Fund was founded in 2011, with the mission to materialize a wide program for maximizing the proceeds of the Hellenic Republic from the development and sale of assets, in order to reduce the public debt burden. Referring to Xenia Hotels, this aims for money without considering rules or regulations for private investors in order to preserve and reuse the hotel compounds.
}

The decline of the Xenia Hotels came due to the turn to mass tourism, bad management, uncontrollable and unregulated construction of new hotel compounds during the period of the military dictatorship in the years 1967-1974. The fact that Xenia Hotels are recognized as "building constructions that further the development of architecture in Greece" according to the theorist Panayiotis Michelis (1962) [3], which consists of "the most important production of public buildings in post-war Greece, achieving through the integration of the settlements in the peculiar and primeval Hellenic landscape, the establishment of a contemporary, pure, and sincere architectural expression, which interpreted the origins of modernism through a deep comprehension of the local cultural references" [4], and that they are characterized as "cultural heritage of the Greek and European architecture of the 20th Century" [4], did not stop the disregard and the destruction of many of them $^{6}$, in an environment where tourism policies do not express anymore stable architectural objectives and vision.

\section{Architectural Characteristics of the Xenia Hotels}

Up to the 1950s, major hotel compounds were very few and situated in chosen, well known touristic sites. The GNTO's Management Council, of which two important and internationally recognized architects were members, Anastasios Orlandos and Periklis Sakellarios, decided, within the frame of its new tourism policies, to assign the invention of new architectural standards for tourist accommodation to a selected team of architects.

The Xenia project, except for large hotel resorts, included many complementary programs for tourist pavilions, stations, motels, regeneration of spa-towns

\footnotetext{
${ }^{6}$ From an official letter written by the Administrative Council of the Association of Greek Architects (Document No. 30517/11-6-2003) to the Ministry of Environment, Energy and Climate Change, and the Ministry of Culture and Sports, for retaining the buildings of the Xenia project as modern cultural heritage.
} 
and also for optional destinations sites of natural beauty, with touristic interest in the mainland and the islands, in areas that had not yet developed their touristic substructures. The aim for building qualitative hotel compounds in these areas was to attract high class international tourists.

The organization's orientation towards the creation of architectural standards becomes clear both from the two eminent architects mentioned above [1], as well as from the creative team of young architects staffing the technical bureau who were well educated, most of them devoted to modernism, and who worked under the supervision of the inspired and experienced Sfaellos and Konstantinidis, heads of the bureau. Architectural options became one of the most serious practices for the tourism policies of the organization. The architectural standards, which were developed through their work, were based on a solid theoretical knowledge, also expressed in Konstantinidis' writings. These standards can be summarized as follows [5]:

- the importance of the location and land chosen covering many of the design aspects, from the building's scale, the microclimate components of the region-orientation, sun penetration, rainfalls, wind fields and natural cooling, the local materials, also the capacity of the building substructures to support the potential tourism development, as well as the local life and existing local culture;

- the sizes and standardization of the buildings as a whole, concerning their functional organization, their morphological and constructive rationality, always taking into consideration the local conditions, as well as individual parts of them, for example, the rooms;

- the holistic design, where the configuration of the surroundings, the building shells and the interior spaces, in all their details, structure a common unit, share the same minimal aesthetics and complete each other.

Based on the above, the Xenia Hotels that were built, despite their different characteristics and the uniqueness of each one of them, shared common design fields in their chosen locations with exceptional natural beauty, thus were recognized as landmarks, and also in the way they were embedded either into the natural or urban environment. Their harmonic integration in the ground's curves with low heights (one, two or rarely three floors), reveals the adaptation to the human scale in most of the settlements. The utilization of natural local materials combined with modern ones (basically, concrete without any plaster and metals) [6], as well as the study of the local traditional architecture, and the discussion about volumes and analogies, complete this integrative procedure (Fig. 1).

The microclimate conditions define important design decisions, concerning the evaluation of the orientation (south or east for most of the openings, north for cooling) for maximum benefit of solar penetration, wind cooling, etc., as well as the connection between the surrounding and the built environment, through transitive enclosed open spaces, which connect the inner and the outer space. As mentioned by Konstantinidis [6]: "let me see the way you build and I will tell you who you are. Not something entirely finished. Not something closed and unreachable. A place, where inner and outer spaces compose an organic entity. The interior space comes

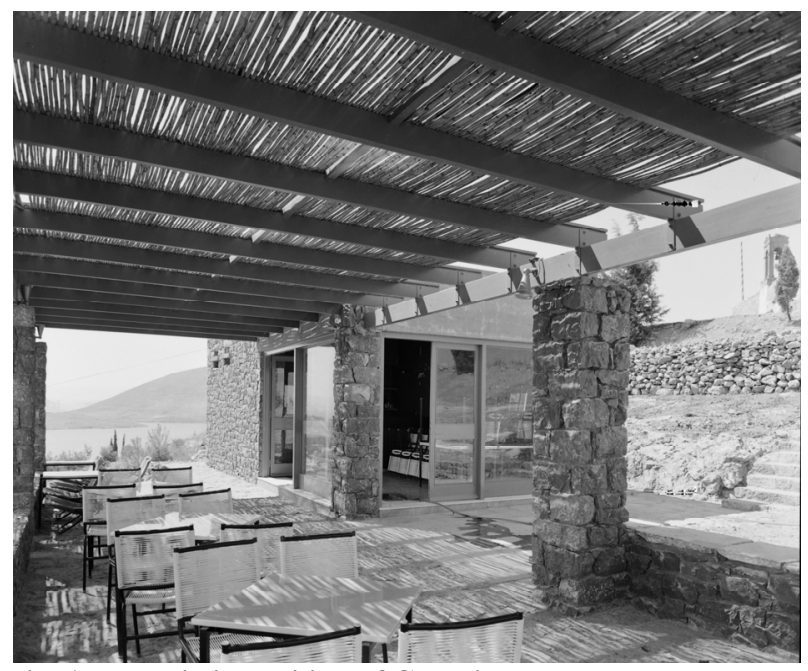

Fig. 1 Tourist's pavilion of Chalkida.

Source: Benaki Museum photographic archives, photo by Dimitrios Charisiadis. 

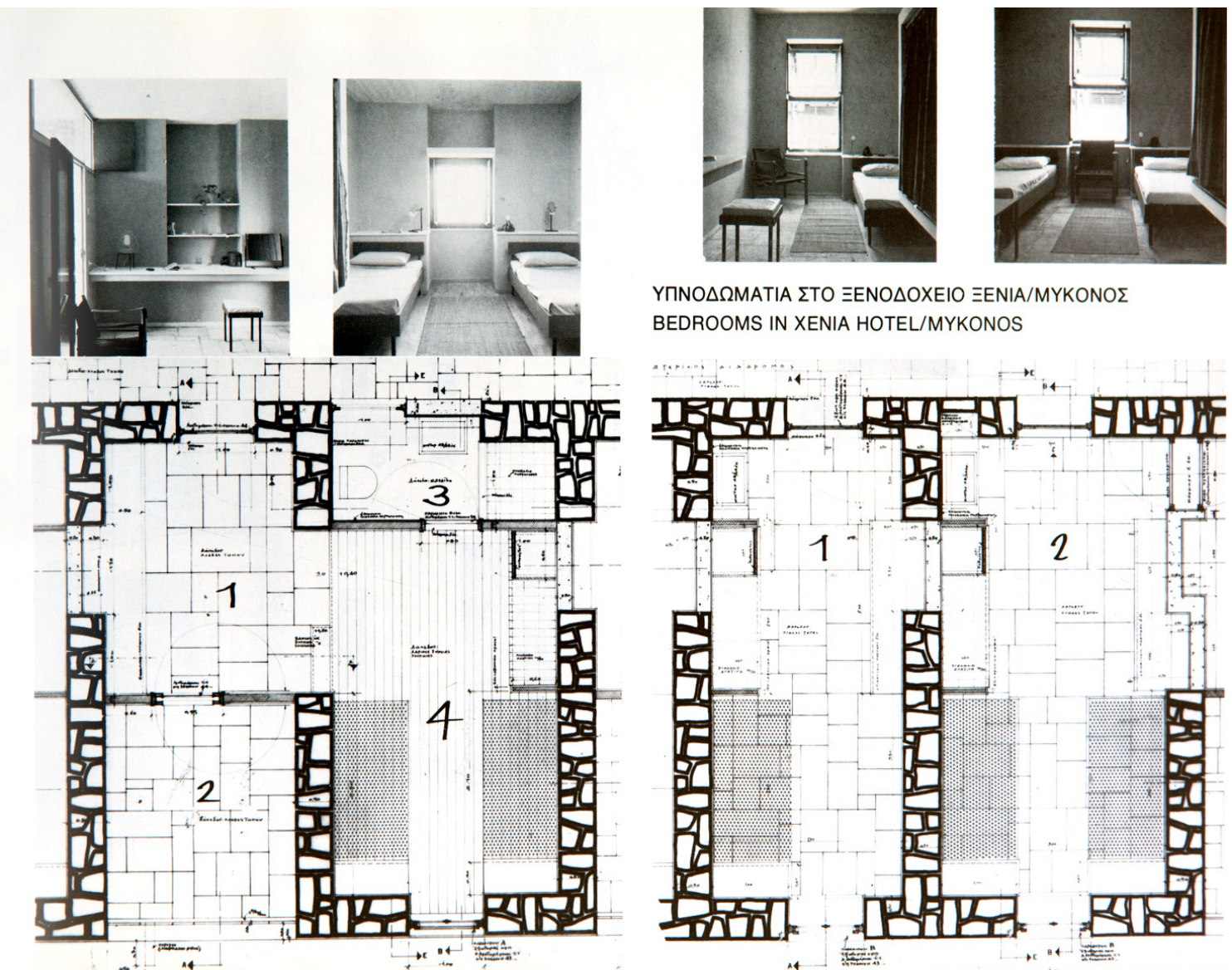

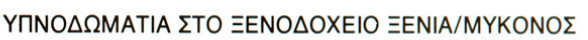
BEDROOMS IN XENIA HOTEL/MYKONOS

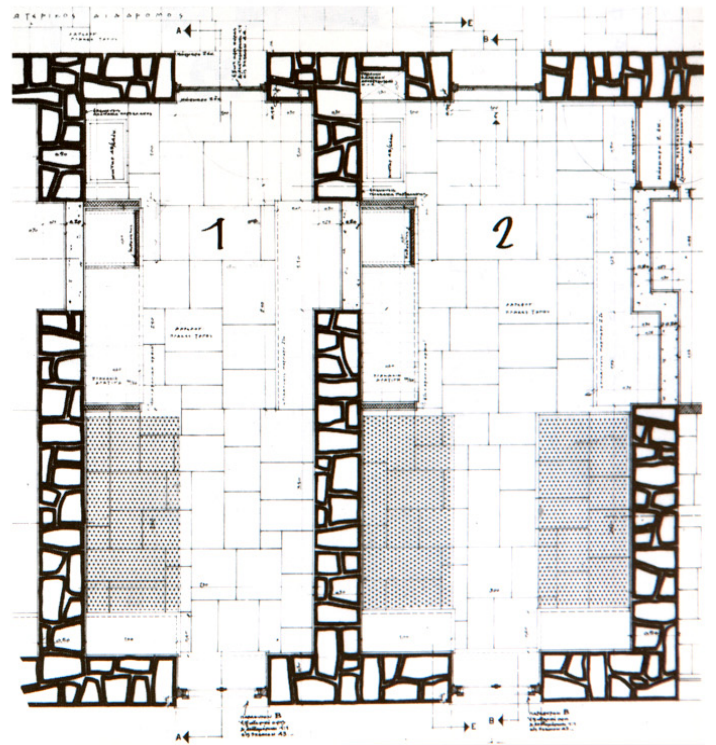

Fig. 2 Xenia of Mykonos island (1960): bedrooms (architect: Aris Konstantinidis).

Source: Projects + Buildings [7].

out to the open space. The outer space penetrates the interior space. And they become one. All of us participate in the same procedure. What is for the first is also for the other-a construction with mental content, for a common quota, for a widespread balance" and "so in the houses I have built... even in all the Xenia, I have put in the right positions, one, or two or even more enclosed open spaces, which made every building pleasantly 'dwellable'. Because of these semi-enclosed spaces, these spaces that are in between, between the inner and the outer spaces, give the opportunity to every human being to stand better on his 'dimensions', to live in accordance with nature, opening a dialogic conversation, which will offer them so many pleasures and beauties" [6].

The functional configuration is standardized with the use of a wing's system, especially for the bedrooms, with a clear flow of movement in the internal spaces, as well as in the surrounding area, closer and further [7]. The functional grid, which arises out of a simple architectural structure of typical parts, is identified with the constructive grid, which is made of concrete without any plaster. The public spaces are separated from the private rooms, often with the use of transitive enclosed open spaces, as mentioned above. The standardization is focused on the basic repetitive module, which is the room, from its construction to the furniture and lightening used, aiming at saving money (Fig. 2). The projects have detailed designs, and nothing is unintended - the balconies, the windows, external louvers, the corridors, the cane sun screens [7].

"And here I am, where I have been looking for ways to have standardization for the construction, and 
also for the functional configuration, thus each architectural work not to be a unintended incident, but to be a work of thought, something that aims for being complete and perfect" [6].

These general characteristics are what built the vision of the Xenia project, which led to the major production of public buildings, during the post war period. However, this architectural treasure, which is internationally recognized as part of our modern cultural heritage, based on the simplicity, the definition of the form and the truth in materials use, and on the integration of the buildings in the natural environment, components which reveal them as a unique venture [3], lies abandoned, time-destroyed, void and unoccupied. Some of these settlements are still in use, having undergone dramatic interventions which altered their aesthetic meaning, while extensions and adjuncts that have come about due to entrepreneurs' occupancy have changed their earliest architectural inspiration [8].

Thus, despite the national and international efforts mentioned above, mainly by the Association of Greek Architects, to retain the Xenia Hotels, these procedures should remain incomplete. They rightly focus on architectural shells, morphological and functional standardization, proper utilization of the Greek environmental conditions, and the use of authentic local materials. However, the cultural evaluation of these settlements can only be completed by their holistic design, which also comprises their interior spaces, lightening and furniture design, all these detailed aspects that form an organic entirety and are not included in these efforts. This paper suggests that this organic entity has to be treated as an unsegregated whole.

\section{Holistic Design and the Interior Space of Xenia Hotels}

The significance of the organic entirety was a widely accepted design concept, at least until the establishment of specialized areas, such as architecture, interior architecture, furniture design, industrial design, etc., in this procedure ${ }^{7}$. This aspect prevailed in the work by many Greek architects during the post-war period, including, Pikionis [9], Konstantinidis [10], Krantonellis [11] and others.

Pikionis in his work Xenia of Delphi (1955) [9], which was designed with his colleague Papageorgiou, as well as Konstantinidis in Xenia of Andros (1958), Poros (1964) and Mykonos (1960) islands [10], was not only involved in the architectural design of the shell, but was also actively involved in the detailed design of the furniture pieces, the style of the interior spaces and the color combinations used.

"The smallest detail and the general, total shape and size, should come out of the same spirit, in the same sensation, through the same vein, for a minimal perfection. The walls, the ceilings, the casings (doors, windows, dormer windows), the fireplaces, the closets, with them and the entire furniture, should have common characteristics. As the same in nature, the trees, the bushes and the flowers compose a world with the same essential core. And as everything, they taste the same and talk the same language. Thus all the constructive elements coexist, so that if one of them is missing, the other one is lost" [6]. The basic principles established in the general synthesis concern minimal forms, authentic local materials, colors and textures, as well as standardization, and are also the basic aspects in the interior space design of the hotel resorts (Fig. 3).

From the photographic archival material, we can notice this perception of "decoration" 8 , not as a

\footnotetext{
${ }^{7} \mathrm{Up}$ to 1950 , the common practice, with several exceptions, was for architects to complete their design, which included the architectural shells, as well as all the decorative elements of the project, furniture design and color, without any support from or co-operation with other specialties, such as interior designers, industrial and furniture designers, etc.. This was due to the fact that these specialized areas were established during the following decades.

${ }^{8}$ Something that opened to international discussions, as in early 1910s, by A. Loos, Le Corbusier, P. Jeanneret, W. Gropius, etc., within an effort of disconnecting architecture from decoration as a filler, and connected it with industrial production's principles to a new aesthetic perception, with standardization as the main characteristic.
} 
covering or incoherent concept, but as an integral element of the architectural synthesis in accordance with the principles of the modern movement [12]. The standardization of the equipment is achieved within modernity, through functionality, the combination of traditional and modern materials (usually wood and metals) and the aesthetics of industrial standards which prevail, whether they are common works (for example, furniture in the lines of Scandinavian design), or well recognized pieces (such as Barcelona by L. Mies Van der Rohe 1929, LC2, 3, the grand comfort armchairs by Le Corbusier, 1929, etc.). This aesthetics inspired Konstantinidis to design a series of standardized pieces of furniture for the bedrooms, armchairs for the public spaces and lamps for his Xenia Hotels [7] (Fig. 4). And this is not a separate design attitude as it was incorporated by other architects too, such as Triantafyllidis [13], who in the presentation of his work for Xenia of Nafplio referred to the furniture he had designed, the textiles, the lamps and the art works, which he had assigned to contemporary artists of those years (Fig. 5).

Generally, the forms of the furniture pieces are geometrical, and wood is combined with leather and textiles, which reveal their color and geometrical forms. The special constructions, which are intended for public spaces, are completely integrated in them

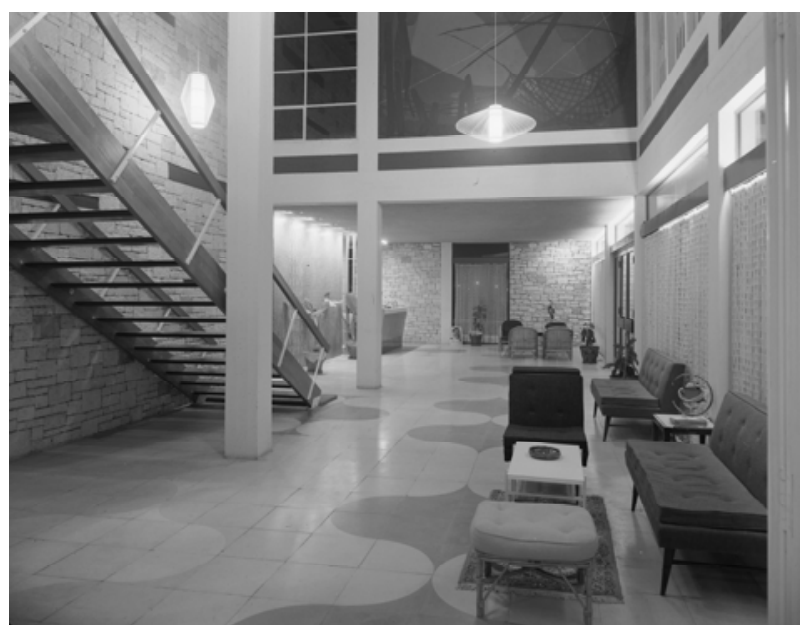

Fig. 3 Xenia of Mesologgi (1958): lobby (architect: Jason Triantafyllidis).

Source: Benaki Museum photographic archives, photo by Dimitrios Charisiadis.
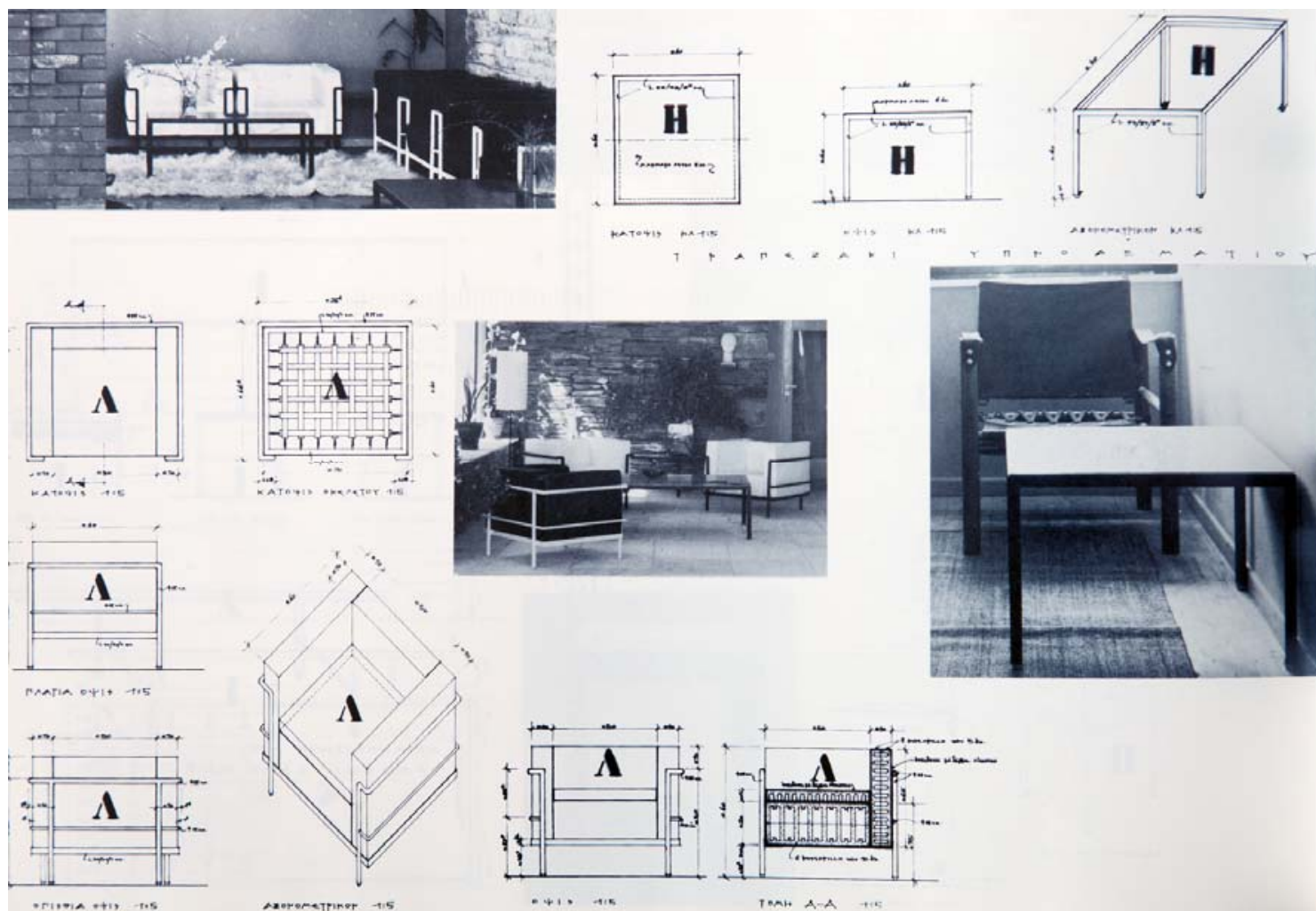

Fig. 4 Armchair and table design for Xenia Hotels, by Aris Konstandinidis.

Source: Projects + Buildings [7]. 


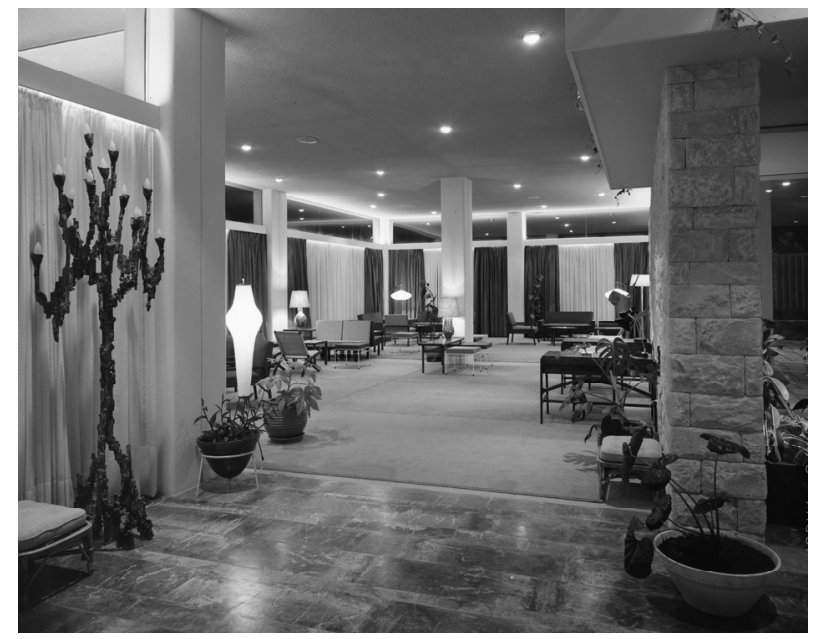

Fig. 5 Xenia of Nafplio (1960): lobby (architect: Jason Triantafyllidis).

Source: Benaki Museum photographic archives, photo by Dimitrios Charisiadis.

(bars, reception desks, shelves, closets, etc.). Decorative motives on the furniture generally do not exist, and in the few cases where we notice them, their presence is so small that it supports simplicity. Metal and wood details are used for the staircases, balconies, rails, dividing walls, etc..

The colors have a visual weight, fulfilling the building's form, assuring the continuity of the inner and outer spaces, optically suiting the geometry of shape. Yellow ochre, terra-cotta red, black, plaster white, sky-blue and indigo blue, these are the ancient Greek colors, which are called by Konstantinidis "grounds" or "Polygnotia colors" [10], and are combined with the natural color of materials such as wood and stone. "Color in architecture is not a decorative coating. Color in architecture works with the constructive structure and is a valuable factor for making each built space an irreplaceable container of life. Because architecture is also made by color" [6]. Thus, the fabrics used on furniture pieces have the color grade of the primary colors, usually in one color, and rarely in geometrical patterns with contrasts. The curtains were also designed using the same principles: there were usually two - an airy fabric, combined with a darker one. In rare cases, mostly in the public spaces, wall patterns are used, where, besides geometrical motives, a variety of other designs can be seen.

Lightening is a specific area of the interior architecture in Xenia Hotels. The recessed lightening is designed, integrated into the construction and structure of each place. In this way, the specific architectural elements (colors, textures, recesses, etc.) are emphasized. In the interior space, the lamps used, especially in the bedrooms, follow the design perspectives, and usually are placed on the walls, or standardized by the architect. Wherever the lamps are placed, they are usually made by a variety of materials, are simply formed and used to reveal the design's aesthetics (Fig. 6).

\section{Preservation of Modern Cultural Heritage}

For the average tourists, as well as for the Greek people, the historical periods that constitute the Greek cultural heritage are summarized to the wealthy periods of the prehistoric and classical archaeology, the Roman and Byzantine archaeology, the local traditional anonymous architectural types, and the neoclassical period which signals the establishment of the contemporary Greek state. The industrial revolution ${ }^{9}$ and, in particular, the modernism period are not featured, among these widely acknowledged historical periods, as their built environment is less recognized, and mostly susceptible to interventions that alter their main characteristics.

The political, social, demographic and economic changes in Greece, the recent rapid growth of the capital city, as well as the current developing economical crisis have changed the built environment, and led to mass alterations into the urban space and their surroundings. On the one side, an urban transformation with the aim of modernizing cities was supported by intensive erection, on the other side,

\footnotetext{
${ }^{9}$ During the last decade, certain cultural foundations have supported the preservation of Greek industrial heritage, with emphasis on its artisanal and industrial technology, thus founding museums such as silk museum, olive and oil museum, ceramic roof-tile and brickworks museum, etc.. Archives, educational and research activities have been established for this purpose on http://www.piop.gr/en/Foundation.aspx.
} 


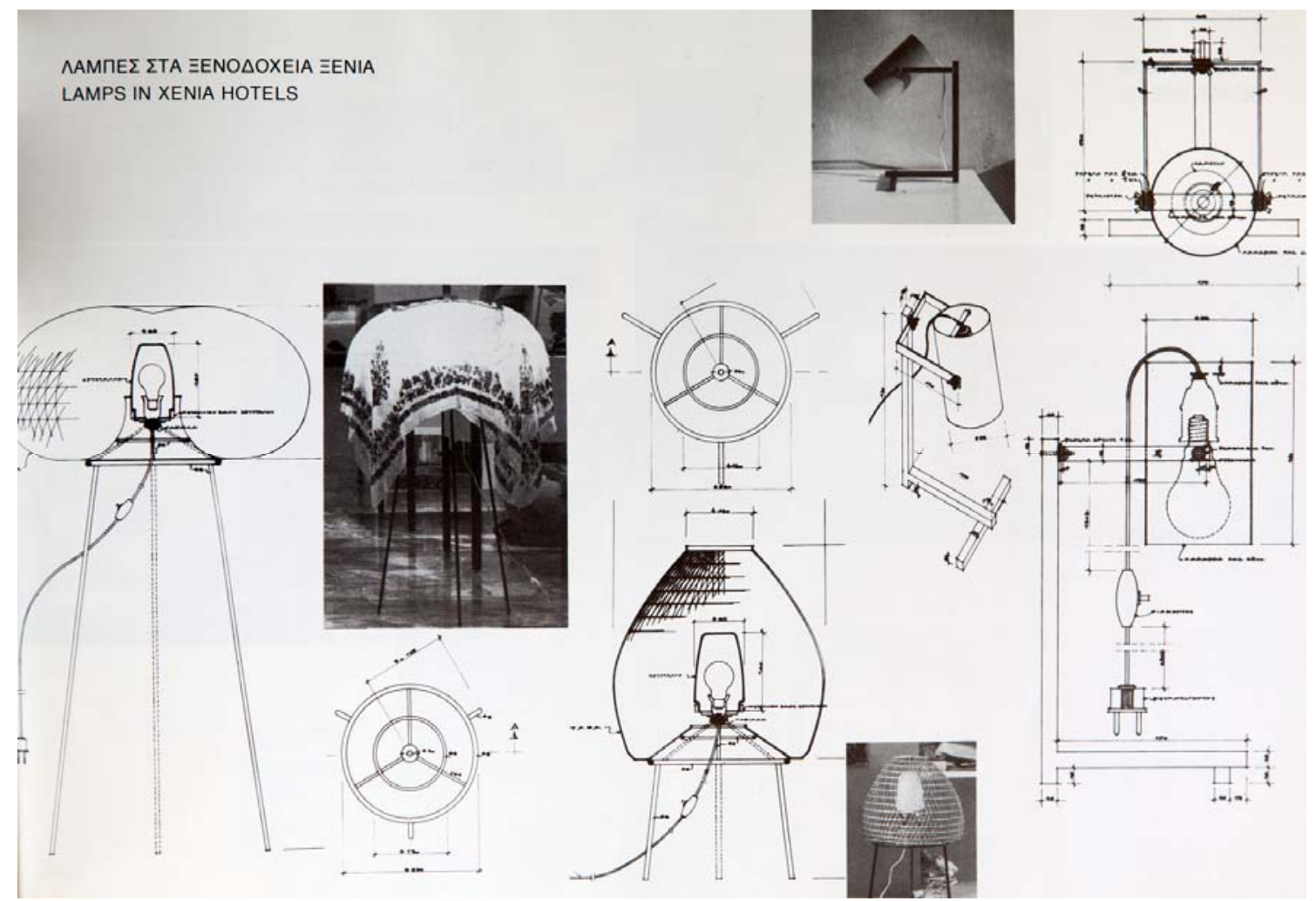

Fig. 6 Lamps in Xenia Hotels, designed by Aris Konstandinidis.

Source: Projects + Buildings [7].

a common acknowledged basis was established, concerning the preservation and conservation of the architectural cultural heritage. The second aspect referred to buildings belonging to the recognized historical periods, and some individual samples of modern buildings of the contemporary period [14, 15]. However, the idea of "preserving the aesthetical meaning of each period, as it is represented at the works left" [16] cannot leave aside contemporary periods and monuments, where their "alive memory" and viability do not even require their use to be changed, in order to preserve them.

The Xenia Hotels, with their architectural characteristics, belong to this category of buildings. Thus, their preservation raises issues for identifying the significance of this type of heritage, as well as establishing criteria for their proposal and nomination for protection. Most of them are not yet nominated to be protected, although they are internationally recognized as Greek modern cultural heritage. The goal for this procedure should be connected with the development of strategies and economical policies in order to value and recognize this built treasure, keeping their characteristics and use connected to the competitive field of tourism development.

According to ICOMOS (International Council on Monuments and Sites) ${ }^{10}$ principles [17] for promoting and managing tourism in ways that respect and enhance the heritage and living cultures of the host communities, in order to encourage a dialogue between conservation interests and the tourism industry: "conservation should provide well-managed opportunities for tourists and members of the host community to experience and understand the local heritage and culture at first hand; the relationship between heritage places and tourism is dynamic and

\footnotetext{
${ }^{10}$ ICOMOS was founded in 1965, in Paris by UNESCO (United Nations Educational Scientific and Cultural Organization), as a non-governmental international organization dedicated to the conservation of the world's monuments and sites.
} 
should be managed in a sustainable way for present and future generations; conservation and tourism planning should create a visitor experience that is enjoyable, respectful, and educational; host communities and indigenous people should be involved in planning for conservation and tourism; tourism and conservation activities should benefit the host community, improving development and encouraging local employment; tourism programs should protect and enhance natural and cultural heritage characteristics". And also in the ICOMOS Charter on Cultural Routes [18], the progression of ideas related to cultural properties is illustrated and the increasing significance of values related to their setting and territorial scale reveals the macrostructure of heritage. Objectives of the charter include: "to establish basic principles and methods of research specific to cultural routes as they relate to previously established categories of cultural heritage assets. To propose essential procedures for the development of knowledge about the evaluation, protection, preservation, management and conservation of cultural routes. To define necessary guidelines, principles, and criteria for correct use of cultural routes as resources for sustainable social and economic development, while simultaneously respecting their authenticity and integrity, appropriate preservation, and historical significance. To determine the bases for national and international cooperation essential for research, conservation, and development projects related to cultural routes".

As been analyzed above, Xenia Hotels represent a holistic design approach, consisting of an organic entity of the architectural shells into the natural environment, the interior spaces, furniture, lightening, colors, textures in every detailed design. In the present situation, some of them are abandoned, unoccupied, time destroyed, demolished, or dramatically altered by their new owners. Their preferential natural sites and cultural recognition could reveal them, as an attractive field for tourism development. These undervalued assets in Greece should be recognized and connected with modern cultural heritage monuments and reinforce this period's cultural routes, adding Xenia Hotels as living and in use prevailed buildings, with positive consequences for tourism development.

\section{Conclusions}

Xenia Hotels are prominent examples of post war public buildings in Greece. They represent an important part of the cultural heritage of modern Greek architecture, reflecting the vision of a team of architects and their innovating ideas for tourism development of the country, based on the ethical model of compensating hospitality ${ }^{11}$.

The Greek state should retain this built treasure that is the Xenia project as a part of the country's history. And this act should include all the morphological and functional options and the vision of their designers: the shells, the inner and outer spaces with all their matching components, which comprise them-stable, moveable, variable, each expressing its individual form and characteristics. Preservation cannot be conceived without considering the surroundings, the shells, the materials, the textures, the equipments, the lightening as indelible parts of the design process. The lack of one of them disturbs the balance of the entity and distorts the holistic procedure of the design, as well as the period expressed through it.

This is a fact noted in many cases: more often than not, reconsidering the initial modern view led to a deformed aesthetics of a new image. Modernization does not mean the change of the synthetic components but the conservation and maintenance of these characteristics that compose the general picture. "Each material has its own voice and a low or high

\footnotetext{
${ }^{11}$ The term is suggested by Panagiotis Ilias. According to Greek mythology, Xenios Zeus was as the god protector of the laws, also protector of the visitors asking for hospitality. This institution has been continued through the Greek tradition. A premise for this is the mutual respect between the host and the visitor. This term is connected with a tourism model that is based on equal respect and economical benefits for both sides, and not in the low side of money earning.
} 
intonation. An architect knows how to reveal this voice and make it resound by agreeably matching materials in a construction and placing them in their proper position. Composing his own music, the architect enables his creation to speak and sing to us and even offer us entire symphonies" [7]. Analogically, every note should remain in place in this design symphony, contributing to the harmony of the sound.

The reused Xenia buildings have been dramatically altered, by their new entrepreneurs. In case studies [5], we mentioned that these alterations concern occasionally either their architectural shell and surroundings, their interior architecture and decoration or all of them. In certain cases (Xenia of Poros, Mesologgi, Nafplio, Nafpaktos among others), new parts have been adapted, something that has ruined the organic unity of the interior and exterior spaces, since the minimal and natural materials used, which were optically connected to the architectural shell and the surroundings, were replaced by others without the same aesthetic quality. The refurbishments have taken away the total identity of minimal and clear morphology, as well as the truth of the constructive and decorative materials, that is to say, the main design perspectives. Color as a component of environmental integration has been changed, without considering its initial sense. On the other hand, the interior spaces seem to be the most susceptible part of new design choices and the easiest way to point towards aesthetic options that are however contrary to the original vision which established them as buildings of modern cultural heritage (for example, interior spaces in Xenia of Drama, Poros, Mesologgi, etc.). Their interior spaces and original furniture have been destroyed, or completely replaced, disrespecting the vision of their designers, as Konstantinidis mentioned in one of his last interviews "the Xenia I have built are unrecognizable - the colors, the furniture everything has changed. And I began wondering why?" [19].
The revitalization of the Xenia Hotels aims for sustainable tourism development and preservation of the remaining resources. It is also an opportunity to discuss and establish criteria and principles for modern cultural heritage preservation, connected with their holistic design approach. Some people may think that keeping them in the same original conditions signals a space and time retreat. But as Chabbi and Mahdy [20] mentioned "in order to have a wide social impact, the preservation strategies should aim to promote living in modern heritage buildings as an attractive option and promote the social status of residing or using modern heritage buildings". Their research refers to house heritage buildings, but it could also occur in hotel buildings of modern heritage. In this case, taking a vacation in a preserved, authentic, modern hotel seems to represent an attractive option and a motive for re-using the Xenia buildings. This does not mean that someone has to refuse contemporary comforts and achievements, and freeze time in the 1960s or 1970s. This procedure represents a challenge for a different approach in the use of existing authentic substructures, considering style and sense of the modern period.

The same authentic design options in the Xenia Hotels also reveal among others an issue of moral nature: public architecture in contradiction to private architecture, according to Konstantinidis [6], allows for the transmission of authentic ideas and the expression of a "true architecture", which signals the moral attitude of the architect as a participant and reflector of the social needs. Within the same morality, the Xenia project has defined the policy for tourism development, as a field for compensating hospitality, with the proper respect to the visitor. This policy includes the built environment, not only as a profitable developing area, left adrift at the hands of private investors, but also as a procedure with rules, boundaries and public control.

\section{References}

[1] Moussa, M. 2012. "Xenia Project 1950-1967. 
Reapproaching the Role of Post-War Modern Architecture in Greece." In Proceedings of 1 st International Conference on Architecture and Urban Design, 503-18.

[2] Philippidis, D. 1984. Newhellenic Architecture: Architectural Theory and Practice (1830-1980) as Reflection of the Ideological Options of the Newhellenic Culture. Athens: Melissa.

[3] Association of Greek Architects. 2004. "Official Nomination for Xenia Hotels by the Administrative Council of the Association of Greek Architects." Journal of the Association of Greek Architects 44: 20-2.

[4] Tzanavara, C. 2008. "Five Xenia Hotels Were Rescued. The First Step Is Made." Eleftherotypia Newspaper, March 3.

[5] Georgiadou, Z., Frangou, D., and Marnellos, D. 2014. "Xenia Hotels in Greece: Rejection or Re-use? A Holistic Approach." In Proceedings of the 4th International Conference on Tourism and Hospitality Management, 20-33.

[6] Konstantinidis, A. 1992. The Architecture of Architecture-Diary Notes. Athens: Agra.

[7] Konstantinidis, A. 1981. Projects + Buildings. Athens: Agra.

[8] Georgiadou, Z., Frangou, D., and Marnellos, D. 2014. "Xenia Hotels in Greece: A Holistic Design Approach." Journal of Tourism Research. Accessed August 1, 2014. http://jotr.eu/index.php/hospitality-management/83-xenia.

[9] Pikionis, A. 1994. Dimitris Pikionis, 1887-1968. Athens: Bastas-Plessas.

[10] Konstantinidis, A. 1975. Elements for Self-cognition for a True Architecture. Athens: Ford Institution.

[11] Kardamitsi-Adami, M. 2009. The Architect Kleon Krantonellis. Athens: Benaki Museum.

[12] Vrychea, A. 2003. Habitation and Houses, Investigating the Boundaries of Architecture. Athens: Ellinika
Grammata.

[13] Hotel Xenia at Nauplia. "Archival Material 1961." Accessed January 13, 2012. http://issuu.com/ sxoliastis/docs/xenia?e=1023644/3199475.

[14] Moschonas, N., and Kallivretakis, L. 1994. "Archaeology of the City of Athens, Digital Edition." Contemporary Monuments Database 1994." The Substation of Public Power Corporation in Athens, a work by Kleon Krantonellis (1971-1977). Accessed May 22, 1995. http://www.eie.gr/archaeologia/gr/arxeio_more.aspx?id=45.

[15] Moschonas, N., and Kallivretakis L. 1994. "Archaeology of the City of Athens, Digital Edition." Contemporary Monuments Database 1994. Round School by Takis Zenetos (1969-70). Accessed May 22, 1995. http://1gym-ag-dimitr.att.sch.gr/istoriko.htm.

[16] Zivas, D. 1997. The Monuments and the City. 2nd ed.. Athens: Libro.

[17] ICOMOS. 1999. "International Cultural Tourism Charter: Managing Tourism at Places of Heritage Significance." ICOMOS. Accessed October 25, 1999. http://www.international.icomos.org/charters/tourism_e.p df.

[18] ICOMOS. 2008. "The ICOMOS Charter for the Interpretation and Presentation of Cultural Heritage Sites." ICOMOS. Accessed October 4, 2008. http://icip.icomos. org/downloads/ICOMOS_Interpretation_Charter_ENG_0 4_10_08.pdf.

[19] Themelis, K. 2000. The Speech of the Master: A Conversation with A. Konstantinidis. Athens: Indiktos.

[20] Chabbi, A., and Mahdy, H. 2011. "Virtuous Circle or Vicious Cycle? Modern Heritage and Development in Abu Dhabi Heritage, Driver of Development." In Proceedings of 17th General Assembly, ICOMOS. Accessed August 1, 2014. http://openarchive.icomos. org/1111/1/I-1-Article7_Chabbi_Mahdy.pdf. 